\title{
How to Improve Lecturers' OCBs?
}

\author{
M. Claudia ${ }^{\mathrm{a}, 1}$, S. Sulasmi \& D. Ratmawati ${ }^{\mathrm{b}, 2}$ \\ aLambung Mangkurat University, Banjarmasin, Indonesia \\ bAirlangga University, Surabaya, Indonesia \\ ${ }^{1}$ meiske.claudia@gmail.com
}

\begin{abstract}
This research aaimed to obtain empirical findings of the influence of perceived organizational support (POS) and workplace spirituality on lecturers job satisfaction, organizational commitment, and organizational citizenship behaviors (OCBs). The population of this study consisted of all permanent lecturers in the University of Lambung Mangkurat (ULM). Respondents were taken from four academic ranks (lecturer, assistant professor, associate professor, and professor). The data were analyzed by using Descriptive Statistic Analysis and Partial Least Square. The results of this study indicated that POS significantly influences lecturers' job satisfaction but insignificantly influences lecturers' organizational commitment or OCBs; workplace spirituality significantly influenced not only lecturers' job satisfaction but also lecturers' organizational commitment and OCBs; job satisfaction significantly influenced lecturers' organizational commitment but insignificantly influenced lecturers' OCBs; and organizational commitment significantly influenced lecturers' OCBs. Both job satisfaction and organizational commitment could partially mediate the influence of workplace spirituality on lecturers' OCBs.
\end{abstract}

Keywords- organizational support; organizational citizenship behaviors

\section{INTRODUCTION}

Several studies in the field of higher education state that the existence of a lecturer is one of the factors determining the success rate of students in the process of transformation of science and technology as well as ethical and moral internalization. The existence of a lecturer is expected to encourage students to study in earnest and optimize their capabilities, although it also depends on students' own willingness. As Henard \& Roseveare (2012) stated that quality teaching in higher education matters for students learning outcomes.

In the context of organizational behavioural sciences, various problems faced by lecturers can be associated with the demanding roles that they hold, a lack of resources, as well as the limitations of what is expected to be obtained on the job. These problems become an obstacle to the realization of one of the three important roles of a lecturer in the organization, particularly the extra role of behaviours, as known as Organizational Citizenship Behaviours (OCBs).

The discussion about OCBs would not be separated from the concept of organizational and workplace spirituality. Perceived Organizational Support (POS) implies the extent to which an organization is considered appreciative to the values of employee contributions and care about their welfare. Workplace spirituality implies the extent to employees' perception that the workplace where they run their profession has spiritual values. In addition, to encourage every member of the organization performing extra role behaviours, the attitudes associated with the work itself (work-related attitudes) should also be considered. Greenberg \& Baron (2003) mentioned that the attitudes related to work such as job satisfaction and an employee organizational commitment [6]. These two attitudes will encourage them to work beyond their formal role.

\section{A. Research Problem}

Based on the problem formulation, the research questions that arise are:

1. Does POS significantly influence ULM lecturers' job satisfaction?

2. Does POS significantly influence ULM lecturers' organizational commitment?

3. Does POS significantly influence ULM lecturers' OCBs?

4. Does workplace spirituality significantly influence ULM lecturers' job satisfaction?

5. Does workplace spirituality significantly influence ULM lecturers' organizational commitment?

6. Does workplace spirituality significantly influence ULM lecturers' OCBs?

7. Does job satisfaction significantly influence ULM lecturers' organizational commitment?

8. Does job satisfaction significantly influence ULM lecturers' OCBs?

9. Does organizational commitment significantly influence ULM lecturers' OCBs?

\section{B. Research Target}

The target of this study was to obtain empirical evidence in explaining the relationship between POS and workplace spirituality towards OCBs through the creation of job satisfaction and organizational commitment. The existence of empirical evidence will become the basis to give certain recommendation to board of university and faculty leaders in formulating organizational policies related to organizational support provided to the lecturers as well as in creating workplace spirituality so they may increase lecturers' job satisfaction and organizational commitment and at the end encourage the 
emergence of OCBs among lecturers in favour of organizational efficiency, effectiveness and creativity.

\section{Perceived Organizational Support (POS)}

POS is defined as an employee perceptions regarding the extent to which the organization gives support to employees and the extent of the organization's readiness to provide assistance when needed (Pack, 2005). According to Rhoades and Eisenberger (2002), POS refers to employee perception of organizational support regarding to the extent organizations value their contributions and care about their welfare. If the employees consider they receive high level of organizational support then the employee will unite the membership of the organization into their identities and then develop a relationship and a more positive perception about the organization. With the united membership in the organization and the identity of the employee, the employee will have a sense of belonging and obligation to contribute and give their best performance to their organization.

\section{Workplace Spirituality}

Robbins (2005) stated that" the concept of workplace spirituality draws on our previous discussion of topics such as values, ethics, motivation, leadership, and work/life balance". $\mathrm{He}$ also stated that "workplace spirituality recognizes that people have an inner life that nourishes and is nourished by meaningful work that takes place in the context of community. Organizations that promote a spiritual culture recognize that people have both mind and a spirit, seek to find meaning and purpose in their work, and desire to connect with other human being and be part of community". According to Mitrof \& Denton (1999), workplace spirituality is defined as "the effort to find one's ultimate purpose in life, to develop a strong connection to co-workers and other people associated with work, and to have consistency (or alignment) between one's core beliefs and the values of their organization". Milliman et al. (2003) states that there are three dimensions of workplace spirituality which are:

a. Purpose in one's work or " meaningful work"

b. Having a "sense of community"

c. Being "alignment with the organization's values".

\section{E. Job Satisfaction}

In a broad sense, Jernigan et al. (2002) reports that job satisfaction is defined as one's sense of satisfaction not only with the work but also with the larger organizational context within the existing work. Thus, job satisfaction is not only related to satisfaction with work itself but also related to the broader organizational context that relates to the job.

\section{F. Organizational Commitment}

The development of research on the construct of organizational commitment gave rise to various views, such as a consensus on organizational commitment in a multidimensional context. For example, Allen \& Meyer (1990) introduce the construct of organizational commitment in three dimensions, namely (1) affective commitment as an emotional attachments to organizations where employees identify themselves to the organization and enjoy the membership of the organization; (2) continuance commitment that is related to the costs occurred when leaving the organization, and (3) normative commitment as a feeling of responsibility to remain in the organization.

\section{G. Organizational Citizenship Behaviors (OCBs)}

Organ et al. (2006: 8) defines OCBs as the employees' extra-role behaviors in a working group, in which they like to do other tasks beyond their job description. Explicit action is not recognized by the formal system of the company, but it can improve the overall organizational efficiency and effectiveness. There are seven types of extra-role behaviors or OCBs explained by Organ et al. (2006: 297), namely: (1) helping behavior, (2) sportsmanship behavior, (3) organizational loyalty behavior, (4) organizational compliance behavior, (5) individual initiative behavior, (6) civic virtue behavior (sincerity), and (7) self-development behavior [17]. 


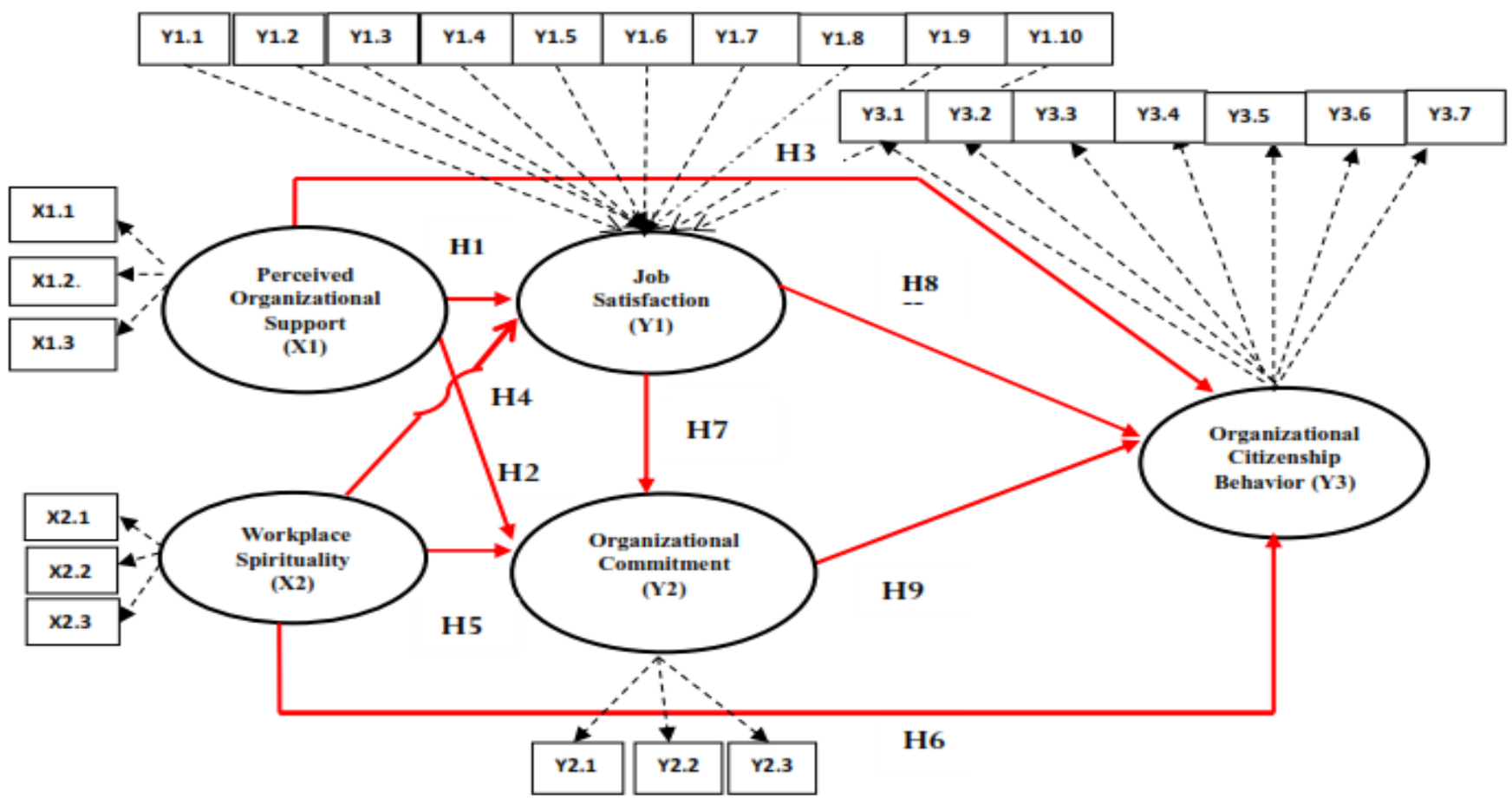

Fig 1. Conceptual Framework

This section briefly describes the conceptual model used in this study along with the formulated hypothesis based on the relationship among variables.

$\mathrm{H}_{1}$ : POS significantly influences ULM lecturers' job satisfaction.

$\mathrm{H}_{2}$ : POS significantly influences ULM lecturers' job satisfaction.

$\mathrm{H}_{3}$ : POS significantly influences ULM lecturers' OCBs.

$\mathrm{H}_{4}$ : Workplace spirituality significantly influences ULM lecturers' job satisfaction.

$\mathrm{H}_{5}$ : Workplace spirituality significantly influences ULM lecturers' organizational commitment.

$\mathrm{H}_{6}$ : Workplace spirituality significantly influences ULM lecturers' OCBs.

$\mathrm{H}_{7}$ : Job satisfaction significantly influences ULM lecturers' organizational commitment.

$\mathrm{H}_{8}$ : Job satisfaction significantly influences ULM lecturer's OCBs.

$\mathrm{H}_{9}$ : Organizational commitment significantly influences ULM lecturer's OCBs.

\section{METHOD}

\section{A. Research Design}

This study was an explanatory (causality) study that aimed to find explanations of the relationship between variables using hypothesis testing which results can be used as a basis for generalization (Sekaran, 2003: 126). Primary data was collected using questionnaire survey technique.

\section{B. Population, Sample Size and Sampling Techniques}

The population in this study was all of 1022 ULM lecturers whose status is as Civil Servants that spread across 10 faculties. Sample size in this study was 130 lecturers selected through cluster-proportional stratified random sampling.

\section{Research Variables Classification}

Based on the pattern of causality in Figure 1, the various latent variables used in this study can be classified as follows: independent variable (exogenous) represented by POS and workplace spirituality; mediating variables (intervening) is represented by job satisfaction and organizational commitment; while the dependent variable (endogenous) represented by OCBs.

\section{Research Instruments}

This study used survey methods with questionnaire as the instrument to collect data. Statements in the questionnaire were made in a close-ended questionnaire that consists of 5 (five) points of Likert Scale. 


\section{RESULT AND DISCUSSION}

Respondents in this study consisted of Chairmen of the Program or Head of Department taken as a separate sample to give an assessment to ULM lecturers' OCB as their subordinates. Lecturers selected as respondents were the source of the data as well as the subject of the study. The chairmen of the Program and Head of Department were considered formally authorized to objectively assess the lecturers who become their subordinates compared to lecturer's self-assessment on their OCB. The unit of research analysis was done at the individual level. All the 130 questionnaires were returned, giving a $100 \%$ response rate and all of them were fit to use in our analysis. There was no missing value in the whole sample.

\section{A. Results of Validity and Reliability Test}

Validity test results in this study can be seen in Table 1. The test results obtained evidence that all research indicators were valid and can be used as an instrument to measure the variables defined in this study. Furthermore, reliability test results in this study used Cronbach Alpha technique as also shown in Table 1. It obtained evidence that all variables in this study have a coefficient of reliability or alpha more than 0.60 .

\section{B. Characteristics of Sample}

The representation of survey respondents based on faculty of origin showed that 25 out of total respondents $(19.23 \%)$ taken from FKIP, 73 out of 130 respondents $(56.15 \%)$ were female, 105 out of 130 respondents $(80.77 \%$ ) hold master (S2) degree qualification, 50 out of 130 respondents $(38.60 \%)$ hold their academic rank as Assistant Professor and 31 out of 130 respondents $(23,84 \%)$ had work tenure between 6 to 10 years.

TABLE I. Test Results of PlS Method of MeAsurement Model

\begin{tabular}{|c|c|c|c|c|c|}
\hline $\begin{array}{c}\text { Latent } \\
\text { Variable }\end{array}$ & AVE* & $\begin{array}{c}\text { Composite } \\
\text { Reliability* }\end{array}$ & R Square & $\begin{array}{c}\text { Cronbach's } \\
\text { Alpha** }\end{array}$ & Communality* \\
\hline X1 & 0.741118 & 0.895301 & & 0.823883 & 0.741118 \\
\hline X2 & 0.815914 & 0.930042 & & 0.887139 & 0.815914 \\
\hline Y1 & & & 0.65511 & & 0.575677 \\
\hline Y2 & 0.586586 & 0.808563 & 0.340141 & 0.643638 & 0.586586 \\
\hline Y3 & 0.678037 & 0.93639 & 0.435999 & 0.920755 & 0.678037 \\
\hline
\end{tabular}

Source: Data processed (2016)

* Valid if AVE and or Communality $>0.5$

** Reliable if Composite Reliability or Cronbach's Alpha $>0.6$

Based on the outcome of the PLS measurement model in Table 1 , the empirical model tested in this research has fulfilled the criteria of the validity and reliability tests. Job satisfaction measurement is considered as formative construct having ten (10) indicators whereas the other constructs are considered as reflective constructs.

The reason of considering job satisfaction as a formative construct based on the understanding that lecturers' job satisfaction is the sum of the satisfaction they might experience to- wards various aspects of their job. In this case, the indicators of job satisfaction construct drawn from the Herzberg's MotivatorHygiene theory.

This study examines nine main hypotheses. Hypothesis testing using the Partial Least Square method was evaluated through the significance parameter of the t-statistics. Table 2 presents the results of the hypothesis testing using the Partial Least Square techniques.

TABLE II. THE RESULT OF PLS METHO OF STUCTURAL MODEL

\begin{tabular}{|c|c|c|c|c|c|c|}
\hline & $\begin{array}{c}\text { Original } \\
\text { Sample (O) }\end{array}$ & $\begin{array}{c}\text { Sample Mean } \\
\text { (M) }\end{array}$ & $\begin{array}{l}\text { Standard } \\
\text { Deviation } \\
\text { (STDEV) }\end{array}$ & $\begin{array}{l}\text { Standard Er- } \\
\text { ror (STERR) }\end{array}$ & $\begin{array}{c}\text { T Statistics } \\
(|\mathrm{O} / \mathrm{STERR}|)\end{array}$ & Result \\
\hline POS (X1) --> JS (Y1) & 0.361026 & 0.374286 & 0.091405 & 0.091405 & 3.949761 & Supported \\
\hline POS (X1) --> OC (Y2) & 0.080799 & 0.061341 & 0.107726 & 0.107726 & 0.750047 & Rejected \\
\hline POS (X1) --> OCBs (Y3) & -0.118355 & -0.128612 & 0.104842 & 0.104842 & 1.128892 & Rejected \\
\hline WS (X2) --> JS (Y1) & 0.522852 & 0.51075 & 0.092825 & 0.092825 & 5.632662 & Supported \\
\hline WS (X2) --> OC (Y2) & 0.201886 & 0.16851 & 0.100801 & 0.100801 & 2.002816 & Supported \\
\hline WS (X2) --> OCBs (Y3) & 0.255238 & 0.247103 & 0.106885 & 0.106885 & 2.387974 & Supported \\
\hline $\mathrm{JS}(\mathrm{Y} 1)-->\mathrm{OC}(\mathrm{Y} 2)$ & 0.350582 & 0.405049 & 0.120654 & 0.120654 & 2.905691 & Supported \\
\hline JS (Y1) --> OCBs (Y3) & 0.150195 & 0.170406 & 0.140174 & 0.140174 & 1.071485 & Rejected \\
\hline $\mathrm{OC}(\mathrm{Y} 2)-->\mathrm{OCBs}(\mathrm{Y} 3)$ & 0.443402 & 0.449783 & 0.076011 & 0.076011 & 5.833418 & Supported \\
\hline
\end{tabular}


Based on the results of the hypotheses testing as seen in Table 2, it can be concluded that 6 of 9 hypotheses were statistically significant. The results were able to explain the link among POS, workplace spirituality, job satisfaction, and organizational commitment as the antecedents of OCBs. The finding of this study is considered important by providing additional empirical evidence regarding the importance of organizational support and workplace spirituality as basis for improving ULM lecturers' job satisfaction, organizational commitment and OCBs. The following section is intended to discuss the results of this study in detail.

Hypothesis 1 stated that POS significantly influenced lecturers' job satisfaction. This hypothesis was statistically supported by the study finding and consistent with a set of previous research of Chiang et al. (2012), Liu (2009), Ekowati \& Andini (2008), Riggle et al. (2009), Beheshtifar et al. (2012), Kuo et al., (2015) and Kurtesis et al. (2015). POS in this study was measured by three indicators, namely fairness, supervisory support, and organizational rewards and working condition. Among these three reflective indicators of POS, the highest average response was on fairness dimension (3.71), followed by supervisory support (3.29) and organizational rewards and working condition (3.21). Higher responses to fairness dimension indicated that ULM lecturers prioritize the application of fairness elements in the implementation of university and faculty policies.

Hypothesis 2 stated that POS significantly influenced lecturers' organizational commitment. This study found that ULM lecturers' POS did not significantly influence their organizational commitment. It means that hypothesis 2 was not statistically supported. This finding was not consistent with the finding of Lew (2009) who found the role of POS on sense of responsibility, affective commitment and low turn-over at private colleges in Malaysia [9]. Furthermore, the results of this study did not support the study finding of Chiang et al. (2012), Liu (2009), Ekowati \& Andini (2008), Riggle et al. (2009), Beheshtifar et al. (2012) as well as Kurtessis et al. (2017). The inconsistency of this study findings compared to previous empirical research was due to university organizational support is given to lecturers which considered as minimal. Related to UU RI No.14/2005 and PP 37/2009 which states that the lecturer as professional educators and scientists, the university leader should provide maximum supports to the implementation of the tasks of lecturers such as transform, develop and disseminate science and technology and the arts through education, research and community service. Besides, the institutional support of the profession of lecturers can be administered in the form of procurement and increased employment/academic activities, an additional source of income, increased expertise, proficiency/skill that meet quality standards as a profession, improvement of academic qualifications, as well as increased competence and responsibility for the execution of tasks as a professional lecturer. In addition, the organizational support from university leader should be guaranteed for the fulfillment of the rights of lecturers in earning an income above the minimum necessities of life and health insurance; promotions and awards; protection of intellectual property; chance to improve their competences; academic freedom, academic forum and scientific autonomy, freedom in giving graduation ratings of students and the freedom of joining association of professional organizations. On the other hand, the fulfillment of the various rights of the lecturer claimed responsibility for the lecturer in the form of an obligation to implement Tridharma Perguruan Tinggi; plan, implement and evaluate the teaching and learning process; promoting and developing academic qualifications; act objectively and non-discriminatively; upholding the legislation, codes of ethics, religious values and ethics; as well as preserving the unity and integrity of the nation. The result of this study explained that the relationship between POS and organizational commitment should be done through the mechanism of job satisfaction formation. The effect of POS on lecturers' organizational commitment can only occur through the role of job satisfaction.

Hypothesis 3 stated that POS significantly influenced lecturers' OCBs. This study found that ULM lecturers' POS did not significantly influence their OCBs. It means that hypothesis 3 was not statistically supported. The results of this study were not consistent with Liu (2009), Miao (2010), Chiang et al. (2012), Yulianti (2015), and Chiaburu et al. (2015) who found a significant relationship between POS and OCBs. The result of this study explains that the relationship between POS and OCBs existed through the role of job satisfaction and organizational commitment.

Hypothesis 4 stated that workplace spirituality significantly influenced lecturers' job satisfaction. As we have already known well, the dimensions of workplace spirituality satisfied higher order needs and spiritual needs of lecturers. The dimensions of the workplace spirituality were proved in encouraging desired affective responses of teachers so there was a positive relationship between workplace spirituality dimensions with lecturers' job satisfaction. These study findings were consistent with Pawar (2009), Amalia \& Yunizar (2010), Altaf \& Awan (2011), Geigle (2012) and Daniel (2012) who found a significant relationship between workplace spirituality and job satisfaction. Based on the above description, it can be concluded that the fourth hypothesis which stated POS significantly influences ULM lecturers' job satisfaction was supported.

Hypothesis 5 stated that workplace spirituality positively influences job satisfaction. The results of this study support the study results of Kumpikaite (2009) which stated that the consequences of spiritual values in the work was employees' commitment. Another study results which support significant relationship between organizational commitment and workplace spirituality were conducted by Rego \& Cunha (2007), Geh (2009), Tan et al. (2009), Pawar (2009), Mulyono (2010), Amalia \& Yunizar (2010), Altaf \& Awan (2012), Daniel (2012), as well as Mousa \& Alas (2016). The results of this 
study were in line with a number of previous empirical studies. This study explained that the mechanisms of workplace spirituality influenced on organizational commitment can occur directly without the role of job satisfaction as mediating variables.

Hypothesis 6 stated that workplace spirituality significantly influenced lectures' OCB. The result was consistent with some previous research conducted by Ayranci (2011) which found that the spirituality of work improved performance. The results of this study supported the notion that workplace spirituality positively influenced employees to work hard and enhanced their extra-role behaviours known as OCBs. In addition, the results of this study also supported previous research conducted by Liu (2008), Rastgar et al. (2012), Ghorbanifar \& Azma (2014), and Charoensukmongkol et al. (2015) which found a significant relationship between workplace spirituality and OCBs. The result of this study explained that the relationship between workplace spirituality and OCBs occurred directly without mediating role of job satisfaction which led to the emergence of lecturers' organizational commitment and OCBs.

Hypothesis 7 stated that job satisfaction significantly influenced lecturers' organizational commitment. This hypothesis was statistically supported by the study findings. This finding was consistent with the study conducted by Dickinson, 2009; Warsi et al. (2009), Zeinabadi, 2010; Norizan, 2012; Mehradi, 2012; Aslam, 2012; Sambung, 2012; Ngadiman (2013), and Amos et al. 2015) which showed job satisfaction as an antecedent to organizational commitment. The relationship between job satisfaction and organizational commitment can occur when members of the organization have a high level of satisfaction within the organization so that they have positive attitude, confidence and trust and a positive perception of the organization. The employees' satisfaction on various job aspects led to the emergence of a strong organizational commitment.

Hypothesis 8 stated that job satisfaction significantly influences ULM lecturers' OCBs. This study found that ULM lecturers' job satisfaction did not significantly influence their OCBs. It means that hypothesis 8 was not statistically supported. This study also did not support the study results of Ahmad (2006) which stated direct positive influence of four (4) working attitude such as organizational commitment, job satisfaction, procedural fairness, and distributive justice on lecturers OCBs. The results of this study were also inconsistent with the findings of Zeinabadi (2010), Muhammad et al. (2011), Ngadiman (2013), Rahman et al. (2014) and Sambung (2012) which found a significant relationship between job satisfaction and lecturers' OCB-O in higher education environments. The result of this study explained that there was no direct relationship between job satisfaction and OCBs but the relationship may exist through the mediating role of organizational commitment. It is found that high job satisfaction could not automatically lead to OCBs but the relationship would exist through mediating the role of organizational commitment that led to the emergence of OCBs.

Hypothesis 9 stated that organizational commitment significantly influenced lecturers' OCBs. The result of this study showed similarities with the findings of other studies assessed the dominant role of organizational commitment dimension on OCB. In general, the result of this study provided support to some previous empirical studies that found significant relationship between organizational commitment and OCBs as conducted by Liu (2009), Geh (2009), Noor (2009), Tan et al. (2009), Zeinabadi (2010), Mohammad et al. (2011) and Ngadiman (2013).

\section{CONCLUSION}

Based on the results and conclusions obtained in this study, some suggestions are proposed as follows:

a. Each faculty dean could improve their lecturers' POS by: (1) encouraging a master degree lecturers to take doctoral program; (2) providing the opportunity and support to the lecturers to immediately obtain the certification of educators so that the lecturer gain more self-confidence to teach, guide students and carry out research and community service; (3) encouraging lecturers/ professors with various areas of expertise to conduct a collaborative research; (4) encouraging doctoral degrees lecturers to conduct high quality research and potential patent to meet the requirements to become Professor and increase the number of professors in ULM by preparing and providing research skim budgetary funding; (5) maintaining Chancellor's commitment to provide incentives to the lecturers who post to good-reputation international journals to significantly increase the number of publications, patents and intellectual property rights; (6) creating a conducive academic atmosphere to foster scientific leadership in building university or faculty research centers to motivate lecturers in conducting a series of scientific activities; (7) encouraging lecturers to prepare themselves for reaching their top career as a professor; (8) supporting the capacity building program by sending lecturers and education staff to nondegree training at various leading universities.

b. Lecturers' perceived workplace spirituality can be improved by providing the initial internalization training to share organizational values, the nature of the profession as an educator and the meaning of work as part of devotion for the new entrants. Faculty leaders need to seek cohesion and interconnectedness among the lecturers by creating a more-friendly working environment and promoting togetherness by occasionally doing outbound activities. Another way to increase workplace spirituality by giving Emotional Spiritual Quotient (ESQ) training and spirituality facilitation in campus area by providing a place of worship or meditation room.

c. Lecturers' job satisfaction could be increased by paying attention to low-scored indicators such as appreciation given 
by the university, faculty, and management, employment policies and procedures, promotion at work, as well as support for the promotion of lecturers' academic rank. The faculty and the university leaders should be able to recognize the contributions of lecturers through an annual basis awards and seek a more transparent culture of communication, which in particular can improve consensus among lecturers in educating and teaching, doing research and community service.

d. Lecturers' organizational commitment can be gained by giving greater support to the development of lecturers' ability/competence to achieve their best performance so then they are expected to have a greater emotional attachment against the institutions and have a willingness to work harder for the sake of organization. Job evaluation can be used to find flaws conducted by lecturers so as providing guidance and facilitation to the lecturers may be granted in order to maximize their ability to produce a better quantity and quality of work. The faculty leaders should be able to work together and communicate openly with one another as well as against the lecturers. Campus officials should have the expertise to support and monitor the lecturers more frequently and easily to find and make a direct approach to the lecturer. Furthermore, the college officials should be able to encourage the lecturers to participate actively in the decision making the process so that the opinions and will of the lecturers that can be transformed into concrete action will gain the recognition of all the academic community.

e. The effort to improve lecturers' OCBs should be considered two (2) main factors such as: internal factors and external factors. Internal factors come from the lecturers' own selves such as moral, lecturers' satisfaction toward his job and organization, lecturers' desire and positive attitude toward his work and organizations. While the external factors should be considered such as the improvement of the management system, the system of leadership and organizational culture.

f. Further research is recommended to consider other variables such as the consequences of OCBs and organizational effectiveness. In addition, further research can also consider the moderator and mediator variables such as age, gender, and length of employment (tenure) into the existing model or add some new antecedents of OCBs such as personality, work climate and organizational culture. In addition, the unit of analysis should also be expanded by including public and private higher education institutions in South Kalimantan to generalize the results. To enrich the OCBs' discussion, further research can also try to examine the negative consequences of OCBs such as increased job stress, work overload and work-family conflict.

\section{REFERENCES}

[1] P.M. Amos, T.S. Acquah, T. Antwi, and N.S. "Adzifome, A comparative study of factors influencing male and female lecturers' job satisfaction in Ghanaian Higher Education," Journal of Education and Practice, vol. 6, no. 4, pp. 1-10, 2015.

[2] M. Beheshtifar, H. Ali-Nezhad and M. Nekoie-Moghadam, "Investigation of perceived organizational support on employees' positive attitudes toward work," Interdisciplinary Journal of Contemporary Research in Business, vol. 4, no. 8, pp. 432-442, 2012.

[3] D.S. Chiaburu, S. Chakrabarty, J. Wang and N. Li, "Organizational support and citizenship behaviors: A comparative cross-cultural metaanalysis," Management International Review, 55 (5): 707-736, 2015.

[4] C.F. Chiang and T.S. Hsieh, "The impacts of perceived organizational support and psychological empowerment on job performance: The mediating effects of organizational citizenship behavior," International Journal of Hospitality Management, vol. 31, no. 1, pp. 180-190, 2012.

[5] D. Ekowati and M. Andini, "Perceived Organizational Support (POS) and organizational commitment," Jurnal Manajemen Teori dan Terapan/ Journal of Theory and Applied Management, vol. 1, no.2, 2008.

[6] J. Greenberg and R.A. Baron, Behavior in organizations: Understanding and managing the human side of work.7th edition, New Jersey, USA: Prentice Hall International, Inc, 2003.

[7] F. Henard and D. Roseveare, Fostering quality teaching in higher education: Policies and practices. An IMHE Guide for Higher Education Institutions : pp. 7-11, 2012.

[8] J.N. Kurtessis, R. Eisenberger, M.T. Ford, L.C. Buffardi, K.A. Stewart and C.S. Adis, "Perceived organizational support: A meta-analytic evaluation of organizational support theory," Journal of Management, vol. 43 , no. 6 , pp. 1854-1884, 2017.

[9] T. Lew, "The relationships between perceived organizational support, felt obligation, affective organizational commitment and turnover intention of academics working with private higher educational institutions in Malaysia," European Journal of Social Sciences, vol. 9, no. 1, pp. 72-87, 2009.

[10] Y. Liu, Perceived organizational support and expatriate organizational citizenship behavior: The mediating role of affective commitment towards the parent company, Personnel Review, 38(3): 307-319, 2009.

[11] R.T. Miao and H.G. Kim, "Perceived Organizational Support, Job Satisfaction and Employee Performance: A Chinese Empirical Study," Journal of Service Science and Management, vol. 3, pp. 257-264, 2010.

[12] J. Mohammad, H.F. Quoquab, and M.A. Allias, "Job satisfaction and organizational citizenship behavior: An empirical study at higher learning institutions," Asian Academy of Management Journal, vol. 16 , no. 2, pp. 149-165, 2011.

[13] A.E. Ngadiman, and D. Ratmawati, "Influence of transformational leadership and organization climate to the work satisfaction, organizational commitment and organizational citizenship behavior on the educational personnel of Sebelas Maret University, Surakarta," European Journal of Business and Management, vol. 5, no. 10, pp. 97 114, 2013.

[14] A. Noor, Examining organizational citizenship behavior as the outcome of organizational commitment: A study of universities teachers of Pakistan. Proceedings 2nd CBRC. Lahore. Pakistan. November 14, 2009.

[15] I. Norizan, Organizational commitment and job satisfaction among staff of higher learning education institutions in Kelantan (Doctoral dissertation, Universiti Utara Malaysia), 2012.

[16] D.W. Organ, P.M. Podsakoff and S.B. MacKenzie, Organizational citizenship behavior: Its nature, antecedents, and consequences. Sage Publications, Inc. Thousand Oaks, CA, 2006.

[17] U. Rahman, W.S.W. Sulaiman, R. Nasir and F. Omar, "The role of job satisfaction as mediator in the relationship between self-efficacy and organizational citizenship behavior among Indonesian teachers," International Journal of Business and Social Science, vol. 5, no. 9, 2014. 
[18] A.A. Rastgar, A. Zarei, S.M.M. Davoudi and K. Fartash, "The link between workplace spirituality, organizational citizenship behavior and job performance in Iran"” Arth Prabhand: A Journal of Economics and Management, vol. 1, no. 6, pp. 51-67, 2012.

[19] A.A. Rego, F. Sousa, M. Pina e Cunha, A. Correia and I. Saur- Amaral, Leader self- reported emotional intelligence and perceived employee creativity: An exploratory study. Creativity and Innovation Management, 16(3): 250-264, 2007.

[20] H. Zeinabadi, "Job satisfaction and organizational commitment as antecedents of organizational citizenship behavior (OCB) of teachers," Procedia-Social and Behavioral Sciences, vol. 5, pp. 998-1003, 2010. 